\title{
Алгоритм формирования трехмерной сцены инфракрасного диапазона
}

\author{
А.В. Зверев, Д.Е. Ипатов \\ ИФП СО РАН, 630090, Новосибирск, пр. Ак. Лаврентьева, 13
}

DOI 10.34077/RCSP2021-139

На сегодняшний день машинное зрение является одним из наиболее значимых применений интеллектуальных систем во множестве областей человеческой деятельности [1]. В таких системах анализ окружения выполняется с применением различных сенсоров, среди которых наиболее распространенными являются фотоприёмные устройства (ФПУ). Для достижения высочайшей эффективности в решении поставленных задач, машинному зрению требуется улучшение следующих качественных и количественных характеристик ФПУ: входной динамический диапазон, латентность по выводу сигнала и возможность работы в инфракрасном (ИК) спектре длин волн. Последнее требование особенно важно в сложных и крайне опасных для человека экстремальных условиях.

Наиболее эффективным способом выполнения первых двух требований является переход от покадрового механизма считывания изображения с сенсора к асинхронному, также известному как Dynamic Vision Sensor (DVS) [2]. Подобный подход представляет изображение на сенсоре в виде потока событий изменения падающей интенсивности излучения на некоторую пороговую величину. Существуют и иные подходы, как, например, свертка картины падающего излучения. Применение подобных методик в реализации ИК ФПУ вероятно позволит достичь высочайшей производительности и эффективности в решении задач машинного зрения.

Однако, разработка данного сенсора требует уточнения ряда его характеристик и тщательного исследования различных вариантов реализации. С этой целью необходимо провести серию экспериментов с предложенной моделью ФПУ. Поскольку в качестве входных данных нельзя использовать видеозаписи с существующих конструкций ИК ФПУ, то в качестве источника данных для модели сенсора будет использоваться ранее разработанный программный комплекс для симуляции трехмерных ИК сцен.

Программный комплекс представляет собой визуализатор произвольных трехмерных сцен широком диапазоне длин волн. В качестве входных данных на визуализатор предоставляются трехмерные сцены формата glTF, сформированные в любом доступном пакете трехмерного проектирования. Трехмерные сцены должны содержать в себе информацию о распределении температур по телу, а также материалы, из которых наблюдаемое тело состоит. Результат визуализации трехмерной сцены представлен в виде распределения числа падающих фотонов на фокальную плоскость сенсора. В данной работе представлен алгоритм формирования трехмерных ИК сцен и особенности разработки симулятора с применением графических процессоров.

\section{Лumepamypa}

[1] J. Horgan et al., Vision-Based Driver Assistance Systems: Survey, Taxonomy and Advances // 2015 IEEE 18th International Conference on Intelligent Transportation Systems, 2015.

[2] C. Posch, et al. Retinomorphic Event-Based Vision Sensors: Bioinspired Cameras With Spiking Output // Proceedings of the IEEE, 102(10), 1470-1484, 2014 